of the brain and spinal column, and the fatal withdrawal of their agency from the respiratory powers. Exposure to the sun, the cerebral circulation being probably in an excited state from previous debauch, is the usual explanation of the modus of the attack. But where is the first point of attack? Is the vitality of the body at once struck? or is the attack upon the nervous or vascular fibre of the brain? Judging from the symptoms of cases of disease that have terminated, some fatally, some in recovery, and from the morbid appearances after death, there cannot, I think, be a doubt that equal states of congestion and pressure, occurring in congestive fever and cholera, are recovered from. Whence then the rapidity and frequency of death in cases of coup de soleil, and the failure of the usual depletory remedies for congestion and pressure on the brain?-Calcutta Quarterly Journal, No. IV.

\section{THE DENTAL CAPSULE.}

\section{To the Editor of ThE LANCET.}

SIR :- Having noticed in your columns of last Saturday my name, and the title of a paper which was read by me at the Medical and Chirargical Society, on the "Persistent Nature of the Dental Capsule," foisted in as an introduction to some puerile and very irrelevant scraps of matter, totally unconnected with that subject, would you allow me to request the young gentleman who takes so much pains to betray his ignorance, to take some care before he again attempts to set up for uritic, to try to comprehend what he is talking about, as he has avowedly not examined the matter at all, and in his extreme ignorance mistakes the inside of the enamel of a tooth for the outside.*

If it were at any time possible to grapple with a nonentity, in this case it would be useless, as the subject will shortly be more fully before the profession; and, moreover, as soon as leisure will permit, $I$ intend to deposit in the College of Surgeons a series of preparations, such as were exhibited to the Medical and Chirurgical Society.

In the meantime, if any one wishes to examine for hinself what I consider an instance of interesting and striking uniformity in the laws of animal organisation,

* We are acquainted with the name of the gentleman by whom the remarks on Mr. Nasmyth's theory were written, and we believe that he is fully competent to treat of most matters connected with the strucsure and physiology of the teeth. let him submit any fresh human teeth, and especially those recently extruded, and con. sequently not yet subjected to much attrition, to the action of diluted muriatic acid (one part of acid to eight parts of water). In a few minutes a membranous covering will be seen to detach itself from the surface of the enamel; and, if then, the action of the acid be discontinued immediately, the enamel will be observed to be almost intact and entire. If the membrane now detached be removed, and the tooth be again submitted to the action of acid, the enamel will soon disappear, leaving the surface of the ivory bare, and no further separation of membrane takes place. The membranes found on the surface of the incisor of the ox and many other lower animals will be found thicker and more consistent. This membrane is the analogue to the thick crust of cementum on the grinders of the elephant and many other animals, and is exhibited in all varieties of thickness through the different classes of animals, from the state of a dense bony investment, to that of an extremely delicate atrophied membranous covering, as in the human species and the carnirora. I am, Sir, your very obedient servant,

March 5, 1839. AleXANDER NASMYTh.

\section{UTILITY OF THE ACT FOR THE REGISTRATION OF DEATHS.}

\section{To the Editor of The LANCET.}

SIR :-A circumstance which you have reported as having occurred in the Registrar's district for Sydenham, brings to my mind a case that happened in my own, and which I forward to you for insertion.

Being Registrar of Births and Deaths for the district of Camden-town, a woman called about a week or ten days ago, to register the death of a child. Upon inquiry as to the cause of death, she told me that the child was suddenly taken ill while at play, and fell down ; medical assistance was called in; but the child did not speak again, and died very shortly afterwards. I consequently refused to register the death until an inquest had been held. Neither the Coroner nor jury thought it necessary to have the evidence of a medical witness, and consequently no cause for the death was discovered. The verdict was " Natural death, by the visitation of God."

Other cases have occurred in which $I$ have refused to register deaths until inquests have been held, in consequence of the death having been sudden and unaccounted for; and I believe similar instances are not un. common in other registries. I remain, Sir, your most obedient servant,

Joseph Curtis, Surgeon.

Camden-town, Feb. 22, 1839 . 